\title{
El derecho de acceso a la información pública en la Provincia de Buenos Aires
}

Aspectos normativos y jurisprudenciales

\author{
Ricardo S. Piana y Fernando M. Amosa
}

\section{El acceso a la información pública como derecho}

El derecho de acceso a la información pública tiene como derecho fundante el derecho humano a la información, necesariamente vinculado a los derechos de libertad de pensamiento y de expresión. En el caso de la información pública, este derecho es un derecho humano, ciudadano y colectivo, basado en el derecho a petición y la obligación de transparencia de la actividad gubernamental, que tiene por principal obligado al Estado.

Decimos que el acceso a la información pública es un derecho humano porque está vinculado con el derecho de todo individuo a recibir ideas e información, elaborarlas y difundirlas, permitiendo la concreción de un ámbito personal de autorealización individual y colectiva ${ }^{1}$ y decimos que es un derecho ciudadano porque sustenta el adecuado funcionamiento de la democracia al ser condición para garantizar otros derechos, en particular el de la participación ciudadana en la gestión pública y el control del gobierno ${ }^{2}$. Afirmamos que es un derecho colectivo

\footnotetext{
1 Como veremos, el carácter de derecho humano ha sido reconocido por la Corte Interamericana de derechos humanos en Corte IDH, "Claude Reyes y otros vs. Chile", Sentencia de 19 de septiembre de 2006.

2 Entendido en su dimensión ciudadana el derecho de acceso a la información pública es un derecho político asentado en ciertas características sobre las que se asienta el régimen republicano (la publicidad de los actos de gobierno y la transparencia de la administración) y el sistema democrático (participación y libertad para seleccionar las diferentes opciones políticas). Publicizada la concepción, aparece como fundamento del acceso a la información en poder del Estado, la prerrogativa que tiene todo individuo de conocer la manera en que sus gobernantes y funcionarios se desempeñan así como el destino del dinero público. La
} 
porque la información a la que se accede es un bien público no individual ${ }^{3}$ que se brinda no sólo a quien la solicitó y que puede libremente difundir quienes a ella acceden ${ }^{4}$.

Dado que el acceso a la información pública, como su eventual difusión, le brinda al ciudadano la posibilidad de desarrollar un pleno ejercicio cívico ${ }^{5}$, pilar elemental para sostener las bases democráticas, cualquier restricción al libre acceso debe estar expresamente prevista, fundada en los ordenamientos jurídicos y acreditado el interés público en la no difusión ${ }^{6}$.

Cabe destacar que en la arquitectura constitucional de los sistemas democráticos contemporáneos, la división de poderes constituye uno de los pilares cardinales para el ejercicio del

propiedad de la información no es del Estado, sino que le pertenece a los ciudadanos, y la posesión de la misma por parte del Estado sólo se justifica en su carácter de representante de la ciudadanía.

3 Sólo se justificaría un perfil individual del derecho en el caso concreto de acceso a los archivos y bancos de datos estatales cuando se requiere conocer información relativa a un dato personal ya que en este caso es "su propia información" o la información de datos inherentes a su persona y no es un "bien colectivo"; no pertenece a la cosa pública aunque dichos datos puedan obrar en archivos estatales y tener la calidad de documento público. Pero entendemos que no debe confundirse el instituto que estamos estudiando con el del acceso y/o rectificación del dato personal (y eventual supresión de datos sensibles) que tienen su propio régimen legal y de protección, Ley № 25. 326.

4 Según Basterra (2017) se encuentra en el plano de los "derechos-autonomía" que tienden a potenciar el ámbito de autonomía de los individuos a efectos de lograr su plena realización, que se dará en orden a la posibilidad de concreción del plan de vida que eligió cada uno. Cumple con una indudable función maximizadora del espacio de autonomía personal, posibilitando la libertad de expresión mediante la estimulación del pensamiento: al acceder a mayor información se toma contacto con una diversidad de opiniones y voces susceptibles de influir o ser determinantes al momento de elegir nuestro proyecto de vida.

5 El resguardo de ambos derechos, acceso y difusión, permite a la vez proteger la libertad de pensamiento y de expresión, necesitando ambas a la información para estimular el pensamiento y la reflexión, en el caso particular, sobre los asuntos públicos. De ahí, como señaláramos, su carácter de derecho humano.

6 Como ha señalado Vallefín (2009), en materia de información pública el acceso constituye la regla por lo que la negativa a suministrarla debería estar sujeta a un test tripartito: 1) la información debe relacionarse con un fin legítimo estipulado en la ley, 2) la divulgación debe amenazar con causar un perjuicio considerable a dicho objetivo y 3) el perjuicio al objetivo debe ser mayor que el interés público de tener esa información. 
control del poder, pero no puede agotarse en él: el otro cimiento está conformado por los derechos fundamentales que viabilizan el campo de acción de la ciudadanía que por medio del voto y la participación en la gestión pública ejercen el último control ${ }^{7}$.

El escrutinio de la ciudadanía sobre el desempeño de su gobierno no puede presuponerse a partir de la mera división de poderes y dispersas manifestaciones republicanas como la publicidad de los actos de gobierno, los debates o el inicio de las sesiones parlamentarias ${ }^{8}$. Para que la ciudadanía tenga capacidad de emitir un juicio sobre los asuntos públicos debe tener acceso a los elementos necesarios para llevarlo a cabo de manera razonada e informada y la posibilidad de que su opinión sea divulgada y confrontada con la de otros individuos?

Así como el principio de razonabilidad del Estado se traduce en el derecho ciudadano a la no arbitrariedad del poder, visto el acceso a la información pública no ya como expresión garantística del principio de transparencia de la gestión, sino como derecho ciudadano colectivo, puede ser estudiado como derecho ciudadano a la ética en la gestión pública o derecho a la "no corrupción"10. En esta línea se caracteriza como un derecho

7 En efecto, la división de poderes, más bien su distribución a través de órganos diferenciados, supone la fiscalización mutua y la colaboración para la toma de las decisiones colectivas. Pero en este esquema clásico, el ciudadano permanecía excluido del proceso inter-poderes. Sólo con la ampliación de la participación ciudadana de la mano de los partidos de masas, el voto y más tarde los institutos de democracia semidirecta, se han consolidado como el otro eje del control, el democrático, que se suma al republicano. Y es en estos últimos años que se va consolidando, como derecho, la participación en la gestión pública que también supone el acceso de la información pública.

8 Basterra (2017) califica a este sistema a todas luces insuficiente y débil. El acceso a la información oficial debe ser en todos los casos la base de rendimiento de las cuentas públicas ya que sólo así se podrá disponer de un catalizador que permita un auténtico control democrático sobre las ramas del poder estatal.

9 Sin posibilidades reales de tener acceso a la información para formar sus propios criterios relativos a la gestión estatal, esto es, sin capacidad para distinguir y juzgar políticas públicas, lo que hay es mera opinión pública que, como sabemos, puede ser fácilmente guiada no sólo por los detentadores del poder sino también por contrapoderes fácticos.

10 La construcción del derecho colectivo a la no corrupción tuvo desarrollos interesantes doctrinarios. Inicialmente expuesto por Luis Carello en 1998, pero continuado por otros como 
público subjetivo en favor de los gobernados que impone deberes a los órganos estatales, puntualmente de realizar su gestión pública en el ámbito administrativo con apego a la legalidad y ética en la gestión ${ }^{11}$.

\section{El derecho al acceso a la Información Pública en el plexo normativo jurisprudencial argentino}

El derecho de acceso a la información pública, si bien de reciente cristalización en un complejo normativo, reconoce sus antecedentes en clásicos derechos que hoy forman parte del derecho convencional de derechos humanos.

El art. 19 de la Declaración Universal de Derechos Humanos (1948); el art. IV de la Declaración Americana de los Derechos y Deberes del Hombre (1948); el inc. $2^{\circ}$ del art. 19 el Pacto Internacional de Derechos Civiles y Políticos (1966), el inc. $1^{\circ}$ del art. 13 de la Convención sobre los Derechos del Niño (1989) y la Convención sobre los Derechos de las Personas con Discapacidad (2006) refieren al derecho a la información

Gordillo (2009, 2017) y Buteler (2012), entro otros, ha sido planteado como derecho humano y derecho colectivo.

11 Ello abre las puertas a la problemática de la "transparencia", por un lado, y por el otro al acceso directo a las fuentes primarias de información. La idea de la transparencia administrativa, caracterizada por una evidente carga axiológica, contribuye a la legitimidad de las administraciones, ya que posibilita su permanente control. Mediante la visibilidad, cognositividad, accesibilidad y, por lo tanto, posibilidad de control de los actos de gobierno, se refuerza el concepto de legitimidad democrática. En esta tesitura se inscribe la línea argumental de la Corte Suprema de Justicia de la Nación al destacar que el derecho a la información pública es un elemento de legitimidad para el poder administrador estrechamente vinculado al sistema republicano de gobierno. Lo que además "es consistente con la noción de democracia deliberativa, porque los términos de la cooperación que propone son concebidos como razones que los ciudadanos o sus representantes responsables se dan recíprocamente en un continuado proceso de justificación mutua. En este sentido, el debate público mejora la legitimidad de las decisiones al requerir criterios comprensivos de las distintas posiciones para arribar un consenso entrecruzado, que si bien no conducirá a lo que cada uno desea individualmente permitirá en cambio a lo que todos aspiramos, es decir vivir en una sociedad ordenada sobre la base de un criterio más realista de justicia" (CSJN, 2016, "Centro de Estudios para la Promoción de la Igualdad y la Solidaridad y otros c/Ministerio de Energía y Minería s/amparo colectivo", consid. 18 del voto de mayoría). 
en sentido amplio ${ }^{12}$. En el sistema americano de protección de los derechos humanos, respecto del artículo 13 inc. 1 de la Convención Americana sobre Derechos Humanos (1969) que también consagra el derecho a la libertad de pensamiento y de expresión, incluyendo la libertad de buscar, recibir y difundir informaciones e ideas, la Corte Interamericana de Derechos Humanos ha señalado que:

77. ... la Corte estima que el artículo 13 de la Convención, al estipular expresamente los derechos a "buscar" y a "recibir" "informaciones", protege el derecho que tiene toda persona a solicitar el acceso a la información bajo el control del Estado, con las salvedades permitidas bajo el régimen de restricciones de la Convención. Consecuentemente, dicho artículo ampara el derecho de las personas a recibir dicha información y la obligación positiva del Estado de suministrarla, de forma tal que la persona pueda tener acceso a conocer esa información o reciba una respuesta fundamentada cuando por algún motivo permitido por la Convención el Estado pueda limitar el acceso a la misma para el caso concreto. Dicha información debe ser entregada sin necesidad de acreditar un interés directo para su obtención o una afectación personal, salvo en los casos en que se aplique una legítima restricción. Su entrega a una persona puede permitir a su vez que ésta circule en la sociedad de manera que pueda conocerla, acceder a ella y valorarla. De esta forma, el derecho a la libertad de pensamiento y de expresión contempla la protección del derecho de acceso a la información bajo el control del Estado, el cual también contiene de manera clara las dos dimensiones, individual y social, del derecho a la libertad de pensamiento y de expresión, las cuales deben ser garantizadas por el Estado de forma simultánea (Corte IDH,

\footnotetext{
12 Libertad de opinión, incluyendo el de no ser molestado y de difundirlas; libertad de investigación, de opinión y de expresión y difusión del pensamiento; libertad de pensamiento y de expresión, incluyendo buscar, recibir y difundir; libertad de expresión incluyendo la de buscar, recibir y difundir; igualdad en el acceso a la información y las comunicaciones, respectivamente.
} 
"Claude Reyes y otros vs. Chile", Sentencia de 19 de septiembre de 2006, p. 43) ${ }^{13}$.

Queda entonces, a partir de este fallo, claramente configurado el derecho de acceso a la información pública como derecho humano reconocido por el Pacto de San José de Costa Rica.

En el ámbito nacional, la reforma constitucional de 1994, además de incorporar estos tratados al bloque de constitucionalidad, fijó algunas pautas dispersas respecto al derecho de acceso a la información pública. En el capítulo segundo "Nuevos derechos y garantías" de la primera parte de la Constitución aparece el derecho a la información y el correlativo deber estatal de proveerlo en lo referente a partidos políticos, medioambiente y derecho del consumidor. Así, el art. 38 indica que se les garantiza a los partidos políticos, entre otros, el acceso a la información pública y la difusión de sus ideas; el art. 41 manda que las autoridades proveerán información y educación ambientales para gozar del derecho a un ambiente sano y equilibrado; por último, el art. 42 reconoce a los consumidores y usuarios de bienes y servicios el derecho una información adecuada y veraz, derecho éste que también puede ser incoado frente al Estado.

También resulta relevante reseñar la Carta Democrática Interamericana (2001) que reconoce como uno de los componentes fundamentales del ejercicio de la democracia a la transparencia de las actividades gubernamentales y por otro, la Convención Interamericana contra la Corrupción (1996) ${ }^{14}$, que en el Artículo III inc. 5 promueve la aplicabilidad de medidas destinadas a crear, mantener y fortalecer sistemas para la contratación de funcionarios públicos que aseguren la publicidad, equidad y eficiencia y la Convención de Naciones Unidas contra la Corrupción (2003), ${ }^{15}$ que en su artículo 10 sugiere a los Estados adoptar diversas medidas para aumentar la transparencia en su

\footnotetext{
13 Disponible en http://www.corteidh.or.cr/docs/casos/articulos/seriec_151_esp.pdf

14 Esta Convención fue aprobada por Ley № 24.759.

15 Internalizada por Ley № 26.097.
} 
administración pública, incluyendo lo relativo a la organización, funcionamiento y procesos de adopción de decisiones ${ }^{16}$.

Sin que tengan obligatoriedad normativa, pero marcando un código deontológico de fuerte legitimidad en materia de buenas prácticas en la gestión gubernamental, los documentos elaborados por el Centro Latinoamericano de Administración para el Desarrollo (CLAD) ${ }^{17}$, tienen particular relevancia. Bajo su propuesta, los Ministros de Administración Pública y Reforma del Estado, incluyendo los de Argentina, han aprobado en las diversas Cumbres documentos internacionales referentes a la función pública, el gobierno electrónico y el gobierno abierto, entre otras temáticas ${ }^{18}$. En ellos y, con creciente interés, el acceso a la información púbica aparece como uno de los pilares del buen gobierno, especialmente a partir de la Carta Iberoamericana de Participación Ciudadana en la Gestión Pública donde

\footnotetext{
16 Entre otras, señala: a) La instauración de procedimientos o reglamentaciones que permitan al público en general obtener, cuando proceda, información sobre la organización, el funcionamiento y los procesos de adopción de decisiones de su administración pública y, con el debido respeto a la protección de la intimidad y de los datos personales, sobre las decisiones y actos jurídicos que incumban al público; b) La simplificación de los procedimientos administrativos, cuando proceda, a fin de facilitar el acceso del público a las autoridades encargadas de la adopción de decisiones; y c) La publicación de información, lo que podrá incluir informes periódicos sobre los riesgos de corrupción en su administración pública.
}

17 El CLAD es un organismo público internacional, de carácter intergubernamental que se constituyó en el año 1972 bajo la iniciativa de los gobiernos de México, Perú y Venezuela y su creación fue recomendada por la Asamblea General de las Naciones Unidas (Resolución 2802 - XXVI) con la idea de establecer una entidad regional que tuviera como eje de su actividad la modernización de las Administraciones Públicas como factor estratégico en el proceso de desarrollo económico y social. Institucionalmente es la Secretaría técnica permanente de las Conferencias Iberoamericanas de Ministros de Administración Pública y Reforma del Estado que se realizan en el marco de las Cumbres Iberoamericanas de Jefes de Estado y de Gobierno.

18 Entre ellos señalamos la Carta Iberoamericana de la Función Pública aprobada en Bolivia en 2003, el Código Iberoamericano de Buen Gobierno, aprobado en Uruguay, en 2006, la Carta Iberoamericana de Gobierno Electrónico, aprobada en Chile, en 2007, la Carta Iberoamericana de Calidad en la Gestión Pública, aprobada en El Salvador, en 2008, la Carta Iberoamericana de Participación Ciudadana en la Gestión Pública, aprobada en Portugal, en 2009, la Carta Iberoamericana de los Derechos y Deberes del Ciudadano en Relación con la Administración Pública, aprobada en Panamá, en 2013 y la Carta Iberoamericana de Gobierno Abierto, aprobada en Bogotá, en 2016, entre otros. 


\section{un capítulo está dedicado al "Acceso a la información pública para la participación ciudadana".}

A partir de la consolidación a nivel mundial de las políticas de gobierno abierto $^{19}$ a través de la Alianza para el Gobierno Abierto $^{20}$, el acceso a la información pública se encuentra hoy en el centro de las temáticas para el buen gobierno ${ }^{21}$.

En nuestro país el acceso a la información pública estuvo relegado, durante mucho tiempo, a la mera publicidad de los actos de gobierno, aunque uno y otro no deben confundirse $^{22}$. Este fundamental principio del republicanismo, el de la

19 El llamado gobierno abierto, más allá de toda conceptualización, tiene enormes implicancias prácticas, al punto que es el entorno de ejecución de un conjunto de medidas que si bien no son todas tecnológicas, se sirve de estas últimas para desarrollarse mediante las potencialidades que ofrecen. En el gobierno abierto subyace la idea de abrir al público, en forma libre y gratuita, los datos, añadiendo nuevos mecanismos de participación e incorporación de los sectores no gubernamentales. La tecnología aparece en el escenario contribuyendo a una nueva relación y forma de gobernar, lo cual implica la "apertura" mediante canales de comunicación, fomentándose de este modo la transparencia. El gobierno abierto implica una relación de "doble vía" entre ciudadanía y Estado, posibilitada por la disponibilidad y aplicación de las tecnologías de la información y el conocimiento que facilitan múltiples interacciones entre actores sociales y estatales, cristalizando en vínculos más transparentes, participativos y colaborativos. Supone ampliar la esfera de lo público, abrir la "caja negra del Estado" (conf. Ivanega, 2016) mediante la participación y protagonismo del ciudadano; transparentar la gestión, admitir un mayor protagonismo para la ciudadanía en la administración del gobierno y expandir las posibilidades de brindar más y mejores servicios a través de un mejor acceso a los sistemas de información. Para una mayor conceptualización, véase Oszlak y Kaufman (2014).

20 https://www.opengovpartnership.org/

21 Esta iniciativa tiene a Argentina como uno de los países con mayor despliegue en los últimos años en cuanto a iniciativas. De los actuales 44 compromisos asumidos por nuestro país, la mayoría se corresponde con los de acceso o difusión de la información pública.

22 En efecto, no debe confundirse el derecho de acceso a la información pública con la publicidad de los actos de gobierno. Según Ekmekdjian (1994:151), se entiende por publicidad el "deber de comunicar los actos de gobierno a la opinión pública, para que los ciudadanos tengan la posibilidad de tomar conocimiento de aquellos, de su contenido, de su gestación y concreción, y ejercer el control del poder que les compete". El acceso a la información pública, en cambio, es un derecho más amplio: incluye información que tiene el Estado y que por no traducirse en actos administrativos, insumo principal de los Boletines Oficiales, no tiene, en principio, la obligación de publicitar; nace a partir de la petición ciudadana; supone, a su vez, la posibilidad de difundir esa información, reagrupar y/o producir conocimiento. Por otro lado, mientras que la publicad de los actos de gobierno tiene su base en el sistema republicano 
publicidad de los actos de gobierno, fue generalmente asociado a la publicación en el Boletín Oficial de los resultados de la toma de las decisiones de los distintos poderes (leyes, decretos, sentencias, versiones taquigráficas de los debates, etc.). Este hacer conocer es evidentemente muy limitado pues no permite sino sólo un control limitado y ex post.

Argentina era uno de los pocos países en la Región que no contaba con una ley específica en la materia ${ }^{23}$. Desde fines del 2003 estuvo en vigencia el Decreto $n^{\circ}$ 1172/03 de Acceso a la Información Pública, aunque la Corte Suprema de Justicia de la Nación había marcado un déficit tanto normativo ${ }^{24}$ como en la práctica de su cumplimiento por diversos Organismos del Ejecutivo ${ }^{25}$.

(Díaz Cafferata, 2009), el derecho de acceso a la información pública tiene raigambre en los principios del sistema democrático.

23 Sin embargo, pueden destacarse algunos antecedentes legales, tales como las Leyes $\mathrm{N}^{0} 24.065$ y 24.076 (marcos regulatorios de electricidad y gas); la Ley $N^{0} 24.240$ (Defensa al Consumidor); la Ley № 25.152 (convertibilidad fiscal); la Ley № 25.188 (Ética en la Función Pública), la Ley N 25.675 "Ley General del Ambiente".

24 De todas formas, en este período debe destacarse que en el ámbito nacional, antes de la actual Ley de Acceso a la Información Pública № 27.275, y a partir de este marco normativo, se dio una considerable proliferación de normas que preveían el acceso a la información pública sin llegar a constituir un régimen integral de alcance general, sino que se circunscribieron al ejercicio de ese derecho en sectores 0 ámbitos específicos o que reconocían este derecho en la esfera de su regulación. Entre ellas, la Ley N² 25.831 (Régimen del Libre Acceso a la Información Pública Ambiental), la Ley N²6.047 (Acceso a la información de registros nacionales de sociedades, asociaciones y fundaciones), la Ley N² 26.331 sobre "Protección ambiental de los bosques nativos", la Ley N ${ }^{0} 26.522$ (de radiodifusión); y a nivel del Ejecutivo, entre otros, los Decretos №378/05 (Plan Nacional de Gobierno Electrónico y Planes Sectoriales); y Nº 616/10 (reglamentario de la Ley de Migraciones $N^{0} 25.871$ ).

25 Pueden destacarse el caso "Asociación por los Derechos Civiles c/PAMI" de 2012, donde la Corte nacional sostuvo que "El fundamento central del acceso a la información en poder del Estado consiste en el derecho que tiene toda persona de conocer la manera en que sus gobernantes y funcionarios públicos se desempeñan, mediante el acceso a la información; toda vez (...) que 'la información pertenece a las personas, la información no es propiedad del Estado y el acceso a ella no se debe a una gracia o favor del gobierno. Este tiene la información solo en cuanto representante de los individuos. El Estado y las instituciones públicas están comprometidos a respetar y garantizar el acceso a la información a todas las personas. El Estado debe adoptar las disposiciones legislativas o de otro carácter que fueran necesarias para promover el respeto a ese derecho y asegurar su reconocimiento y aplicación efectiva"'. En 2014, insistió con este argumento en el caso “CIPPEC C/Min. de Desarrollo Social- dto. 1172/03, Amparo ley 16.986" y obligó al Ministerio de Desarrollo Social de la Nación (MDS) a brindarle a una 
Luego de varios proyectos de ley que intentaron modificar este déficit, el actual Poder Ejecutivo Nacional remitió al Congreso un proyecto de Ley de Acceso a la Información Pública, aprobado y promulgado en 2016 como Ley $N^{\circ} 27.275$. Entre los fundamentos, se sostiene que el proyecto se enmarca en el principio republicano de publicidad de los actos de gobierno y en el derecho de acceso a la información pública derivados de los artículos $1^{\circ}, 33$ y 38 de la Constitución Nacional y por los instrumentos internacionales de protección de los derechos humanos a los que el artículo 75 inciso 22 les otorga jerarquía constitucional.

La Ley regula el acceso a la información pública en todas las áreas del Estado, incluyendo el Poder Ejecutivo, el Poder Legislativo y el Poder Judicial, organismos centralizados, descentralizados, empresas y sociedades estatales y cualquier otra entidad privada a la que se le haya otorgado subsidios o aportes del Estado Nacional, entre otros. Se clarifica el alcance de la información pública y enumera de modo preciso las circunstancias y procedimientos que permiten denegar los pedidos de información. Dos artículos del texto son clarificadores del alcance de la norma:

Artículo $2^{\circ}$. Derecho de acceso a la información pública. El derecho de acceso a la información pública comprende la posibilidad de buscar, acceder, solicitar, recibir, copiar, analizar, reprocesar, reutilizar y redistribuir libremente la información bajo custodia de los sujetos obligados enumerados en el artículo $7^{\circ}$ de la presente Ley, con las únicas limitaciones y excepciones que establece esta norma.

Se presume pública toda información que generen, obtengan, transformen, controlen o custodien los sujetos obligados alcanzados por esta Ley.

Artículo $4^{\circ}$. Legitimación activa. Toda persona humana o jurídica, pública o privada, tiene derecho a solicitar y recibir

organización de la sociedad civil datos solicitados en 2008 sobre transferencias en concepto de "Ayuda social a las personas" que había solicitado y que el Ministerio que había negado aduciendo que los mismos eran datos sensibles. Un breve pero interesante análisis a estos casos y otros, puede ampliarse en Berardi (2018). 
información pública, no pudiendo exigirse al solicitante que motive la solicitud, que acredite derecho subjetivo o interés legítimo o que cuente con patrocinio letrado.

Si bien no es materia de este artículo un examen de la Ley nacional $^{26}$, aspectos loables de la $\operatorname{misma}^{27}$ se han visto opacados por el Decreto de Necesidad y Urgencia $N^{\circ} 746 / 17$ en cuanto modifica las competencias de la Agencia de Acceso a la Información Pública, la que pasó a estar en el ámbito de la Jefatura de Gabinete de Ministros, dependiendo ahora de ésta el diseño de su estructura orgánica y la designación a su planta de agentes. Esta dependencia normativa (y política) limita, sin lugar a dudas, la autonomía funcional del nuevo Organismo y los aspectos de control allí previstos ${ }^{28-29}$.

26 Para un análisis más profundo de la norma, nos remitimos a Basterra (2017); Vallefín y López (2017), Funes y Rivas (2016), Gelli (2016), entre otros.

27 Algunos de los principios que determina la ley, además del de legitimidad activa amplia y transparencia activa, son los de presunción de publicidad de toda la información en poder del Estado; informalismo en las reglas para acceder a la información; máximo acceso, esto es, la información debe publicarse de forma completa, con el mayor nivel de desagregación posible y por la mayor cantidad de medios disponibles; apertura (accesible en formatos electrónicos abiertos); no discriminación; máxima premura; gratuidad; responsabilidad; facilitación; buena fe e "In dubio pro petitor", es decir, siempre debe estarse en favor de la mayor vigencia y alcance del derecho a la información.

28 Para garantizar que la norma se aplique, la ley prevé varios mecanismos. En primer lugar, la denegatoria debe hacerse por vía de resolución por la máxima autoridad del organismo 0 entidad requerida que, como tal debe fundarse. Además, el silencio del sujeto obligado, vencidos los plazos previstos (15 días hábiles prorrogables excepcionalmente por otros 15), así como la ambigüedad, inexactitud o entrega incompleta, son considerados como denegatoria injustificada a brindar la información. En ese caso, se abre directamente la posibilidad de recurribilidad ante la justicia sin necesidad de agotar la vía administrativa (arts. 11, 13 y 14 de la Ley). Además, a la Agencia de Acceso a la Información Pública, para garantizar el efectivo ejercicio del derecho de acceso a la información pública y promover medidas de transparencia activa (Capítulo IV del Título I de la Ley), se le encomienda entre las funciones más destacadas, la de implementar una plataforma tecnológica para la gestión de las solicitudes de información y sus correspondientes respuestas así como requerir a los sujetos obligados que modifiquen o adecuen su organización, procedimientos, sistemas de atención al público y recepción de correspondencia a la normativa aplicable así como intervenir, administrativamente ante reclamo del interesado (arts. 14, 15 y 24 de la Ley).

29 Otro aspecto que merece una mayor revisión es haberle asignado a la Agencia, a través de este DNU, competencias en materia de protección de datos personales, entonces a cargo 


\section{Estado actual de la normativa referente al derecho de Acceso a la Información Pública en la Provincia de Buenos Aires}

El derecho de Acceso a la Información Pública tiene base constitucional en nuestra Provincia. La Constitución local reconoce este derecho de los ciudadanos en el art. $12^{\circ}$ inc. 4 cuando enumera que "Todas las personas en la Provincia gozan, entre otros, de los siguientes derechos (...) 4) A la información y a la comunicación". Asimismo, cabe destacar que es deber constitucional de la Provincia promover el desarrollo integral de las personas garantizando la igualdad de oportunidades y la efectiva participación de todos en la organización política. Al igual que en la Constitución Nacional, en materia medioambiental, el art. 28 garantiza el derecho a solicitar y recibir adecuada información, el 38 el derecho de los consumidores y usuarios a una información adecuada y veraz y el 59 el acceso a la información pública a los partidos políticos. También su art. 43 manda la transferencia de los resultados de la investigación científica y tecnológica efectuada con recursos del Estado y la difusión de los conocimientos y datos culturales mediante la implementación de sistemas adecuados de información.

En el ámbito bonaerense no se cuenta aún con un régimen integral de Acceso a la Información Pública ${ }^{30}$. No obstante ello, existe un régimen legislativo limitado al "Acceso a los documentos administrativos" el cual adolece de ciertas limitaciones que seguidamente analizaremos.

En los fundamentos presentados de la que sería aprobada como Ley $\mathrm{N}^{\circ} 12.475$ se señala que ...

\footnotetext{
de la Dirección Nacional de Protección de Datos Personales, dependiente del Ministerio de Justicia. Ambos derechos, de igual raigambre constitucional, pasan a depender de un único organismo que ha sido creado, fundamentalmente, para garantizar el acceso a la información pública mientras que los aspectos vinculados a la protección de datos personales se orientan tanto al sector público como privado.

30 Es importante destacar que una instancia que parece compatible con el acceso a la información y la Participación en el ámbito de la Provincia de Buenos Aires, es la Ley № 15.569 sobre audiencias públicas. Asimismo,
} 
La presente iniciativa (...) pretende resguardar tanto la publicidad de los actos de gobierno, como la efectiva vigencia de la seguridad jurídica. Constituye, en consecuencia, una forma explícita de asegurar la subordinación de la actividad estatal a la Constitución, que es uno de los pilares básicos y fundamentales del estado de derecho. Sin perjuicio de ello creemos que el proyecto también encuentra sustentación en dos necesidades sociales igualmente relevantes: la reforma y modernización de las estructuras estatales y la exigencia de la transparencia de los actos públicos ${ }^{31}$.

Como hemos señalado, no regula un sistema de acceso a la información pública generada, en trámite o en guarda por el Estado, sino solamente crea un ámbito normativo que permite el conocimiento de cierta información generada por el Estado que se encuentre plasmada en un documento administrativo ${ }^{32}$.

En efecto, la Ley reconoce a toda persona física o jurídica que tenga interés legítimo el derecho de acceso a los documentos administrativos a los que define en su art. $2^{\circ}$ como "toda representación gráfica, fotocinematográfica, electromagnética, informática, digital o de cualquier otra especie, que contenga datos o informaciones provenientes de órganos públicos del Estado Provincial cuya divulgación no se encuentre probibida expresamente por la Ley". ${ }^{33}$

Respecto al interés legítimo ${ }^{34}$, que constituye uno de los principales obstáculos de la norma, la Ley requiere que la solicitud de

\footnotetext{
31 La adscripción de la norma no sólo a los principios de publicidad de los actos de gobierno y la seguridad jurídica sino también a la transparencia y reforma y modernización resulta muy interesante para ese momento, año 1999, aprobada en el 2000. Expediente Origen: D- 534/9899 presentado por Mario Luis Espada.

32 Esto es, regula una especie en un género mucho más amplio.

33 La enumeración de los distintos medios lo que pretende hacer es desvincular la información de sus soportes y así podría incluirse información presente, por ejemplo, en las viejas tarjetas perforadas.

34 Es decir, quien tenga interés simple no puede solicitar acceso a los documentos en los términos de esta Ley. La actual Ley Nacional, a modo de comparación con los términos de esta Ley, señala que "Toda persona humana o jurídica, pública o privada, tiene derecho a solicitar y
} 
acceso a los documentos debe ser fundada mediante presentación por escrito firmado en el que consten los datos identificatorios personales del solicitante y ante la dependencia oficial que ha conformado el documento o lo retiene en su poder (conf. art. $5^{\circ}$ ).

El derecho se puede ejercitar mediante el "examen de las actuaciones y la extracción de copias" (art. $3^{\circ}$ ) y si bien se dispone que el examen de los documentos es gratuito, luego se indica que la expedición de copias de cualquier naturaleza está subordinada al pago de un arancel que no puede ser superior a los gastos operativos que demande la obtención de las mismas $\left(\operatorname{art} .4^{\circ}\right)$.

El plazo para contestar el requerimiento es de hasta treinta días hábiles. Si transcurre dicho plazo, la solicitud se entiende denegada. Frente a tales supuestos, en virtud de la existencia de una inactividad, la vía a utilizar por el ciudadano debería ser el recurso administrativo ${ }^{35}$ o el amparo por mora ${ }^{36}$; sin embrago, tanto para el caso de denegación táctica como expresa la ley habilita la interposición de la acción de amparo ${ }^{37}$ o babeas data según corresponda ${ }^{38}$.

recibir información pública, no pudiendo exigirse al solicitante que motive la solicitud, que acredite derecho subjetivo o interés legítimo o que cuente con patrocinio letrado" (Ley № 27.275 art. $4^{\circ}$ ).

35 Entendemos que aún cuando se reconozca agotada la vía administrativa, ello no limita a que el interesado pueda utilizar las vías administrativas que crea pertinentes.

36 Prevista en el art. 76 de la Ley $N^{0} 12.008$ (texto según Ley Nº 13.101)

37 Prevista en el art. 20, inc. $2^{\circ}$, de la Carta Magna local y en la Ley de Amparo No 13.928.

38 El procedimiento de Habeas Data provincial tiene regulación como "proceso constitucional" mediante la Ley $N^{0} 14.214$. Sobre todo hay que tener en cuenta que el régimen previsto tiene aplicación respecto de los titulares y/o responsables y usuarios de bancos de datos públicos, y de los privados a dar informes, administradores y responsables de sistemas informáticos; conceptos que a su vez son definidos y hay que recoger de la Ley Nacional N 25.326 y su Decreto Reglamentario N 1558/01 sobre Protección de los Datos Personales. En la actualidad y en el contexto del Programa Justicia 2020 llevado a cabo por el Ministerio de Justicia y Derechos Humanos de la Nación existe un nuevo proyecto de ley nacional que puede verse en https://www.justicia2020.gob.ar/wp-content/uploads/2017/02/Anteproyecto-de-ley-PDP. pdf. Asimismo la Ley 14.214 de la Provincia, establece la jurisdicción y competencia del Juez de Primera Instancia en lo Contencioso Administrativo cuando se trate de archivos públicos de la Provincia de Buenos Aires. Cabe agregar que la ley señala en su artículo 20 que será de aplicación cuando quien tenga legitimación activa sea afectado por la Ley Nº 12.475. 
Con relación a los límites se establece "que el derecho de acceso puede ser vedado cuando se trate de actos preparatorios $y$ en aquellos supuestos en que su divulgación pudiere perjudicar el derecho de privacidad de terceros o afectar su honor" (conf. art. $6^{\circ}$ ).

Aunque no surja en forma expresa y clara debe entenderse que los alcances de la Ley incluyen a todos los poderes del Estado provincial y sus municipios ${ }^{39}$, entes autárquicos y descentralizados y hoy necesariamente incluirse a las empresas con participación estatal mayoritaria.

A nivel del Poder Ejecutivo, la primera vez que aparece este deber por parte de los funcionarios es con la ley de Ministerios, Ley $\mathrm{N}^{\circ} 13.175$, aprobada en 2004. Allí se establecía entre las funciones comunes de los ministros secretarios la de ...

- facilitar el ejercicio del derecho a la información previsto en la Constitución local, organizando áreas para recibir, procesar, sistematizar y elevar, con rapidez y eficiencia toda propuesta, reclamo, pedido y opinión útil para la formulación, implementación, control de gestión y evaluación de políticas, planes y cursos de acción que provengan de la ciudadanía en general, de sus instituciones representativas y de cada uno de los habitantes de la provincia en particular (art. $9^{\circ}$ inc. 4 );

- confeccionar y difundir la agenda sistémica de su cartera (art. $9^{\circ}$ inc. 5);

- asegurar la transparencia de la función pública, difundiendo el detalle de la utilización de los recursos y el estado del gasto en el ámbito de su jurisdicción (art. $9^{\circ}$ inc. $6^{\circ}$;

- facilitar, a través de los mecanismos apropiados, la participación ciudadana (art. $9^{\circ}$ inc. $7^{\circ}$ ).

\footnotetext{
39 Dado que aún no gozan en Buenos Aires de la autonomía que les garantiza la Constitución Nacional. La actual Ley Orgánica de Municipalidades nada dice al respecto aún cuando hay que reconocer que varios municipios cuentan con normativa específica o que reconocen, en el marco de otras políticas, el derecho ciudadano a acceder a la información pública.
} 
La actual ley de Ministerios, Ley $\mathrm{N}^{\mathrm{o}}$ 14.989, nada dice al respecto. Sin embargo, aún se encuentra vigente para el ámbito del Ejecutivo el Decreto reglamentario No 2549/04. Dicho Decreto pretende crear un sistema idóneo, eficiente y eficaz para hacer operativa Ley $\mathrm{N}^{\mathrm{0}} 12.475 .^{40}$

El Decreto señala que toda persona física o jurídica ${ }^{41}$ tiene derecho de acceso a documentos administrativos de naturaleza pública $^{42}$ y reconoce, ahora sí, que éstos pueden estar o ser generado por organismos, entidades, empresas, sociedades, dependencias y todo otro ente que funcione bajo jurisdicción del Poder Ejecutivo, quienes deberán organizar áreas destinadas específicamente a permitir el acceso, consulta y eventual reproducción de documentos administrativos de su competencia, pudiendo dictar sus propias normas de procedimiento en la medida que favorezcan y no perjudiquen los derechos y garantías ya consagradas (conf. art. $3^{\circ}$ ).

En el Anexo del Decreto, donde se establece un Reglamento General de Acceso a Documentos Administrativos del Poder Ejecutivo, se consagran los siguientes principios del procedimiento de acceso:

- Publicidad: Se presume pública toda información producida por los sujetos legitimados pasivos, así como la obtenida por los mismos. No se consideran públicos los documentos administrativos cuya divulgación pudiere perjudicar el derecho de privacidad de terceros o afectar su honor.

\footnotetext{
40 La norma también preveía iniciar una instancia de consulta pública con el objeto de revisar los alcances de la Ley № 12.475 a fin de garantizar en la forma más amplia y razonable posible el derecho de acceso a la información pública, temática que incluía en la Mesa del Diálogo para la Reforma Política, creada por Decreto № 1786/04.

41 El que "toda persona" sin más adjetivación tenga derecho de acceso a documentos administrativos puede hacer suponer que ya no se exige un interés legítimo, es decir, que la norma regulatoria es más amplia que la ley que reglamenta. Así lo consideró la Suprema Corte bonaerense en los autos "Asociación por los Derechos Civiles contra Dirección General de Cultura y Educación. Amparo. Recursos extraordinarios de nulidad e inaplicabilidad de ley" como más adelante analizaremos.

42 En el art. 3 del anexo del Decreto reproduce la definición de la Ley sobre documento administrativo.
} 
- Celeridad: Los sujetos obligados deben dar respuesta a los pedidos de acceso a documentos administrativos lo más pronto posible.

- Informalidad: El procedimiento de acceso debe desarrollarse sin más condiciones que las expresamente establecidas y aquellas otras que por razones de carácter estrictamente operativo, orientadas a facilitar y no entorpecer el acceso, sean dictadas por cada uno de los sujetos obligados.

- Accesibilidad: Los sujetos legitimados pasivos se encuentran obligados a proveer a una adecuada organización, sistematización y disponibilidad de la información en su poder, asegurando un fácil y amplio acceso.

- Igualdad: Los sujetos obligados deben observar y respetar el principio de igualdad en los procedimientos para el acceso a documentos administrativos.

- Gratuidad: El examen de los documentos administrativos es gratuito. Los costos de reproducción son a cargo del solicitante.

El listado de las excepciones es amplio, aunque exige que la denegatoria deba ser fundada y resuelta por un funcionario de jerarquía equivalente o superior a director provincial ${ }^{43}$.

\footnotetext{
43 Así prevé que el derecho de acceso a los documentos administrativos no se otorgará cuando: a) se trate del examen de actos preparatorios; b) la divulgación de ellos pudiera perjudicar el derecho de privacidad de terceros o afectar su honor; c) se trate de información expresamente clasificada como reservada, especialmente la referida a seguridad, defensa 0 política exterior; d) sea información que pudiera poner en peligro el correcto funcionamiento del sistema financiero o bancario provincial; e) se involucre secretos industriales, comerciales, financieros, científicos o técnicos; f) información que comprometa los derechos o intereses legítimos de un tercero obtenida en carácter confidencial; g) información preparada por los sujetos legitimados pasivos, dedicados a regular o supervisar instituciones financieras o preparada por terceros para ser utilizada por aquéllos y que se refiera a exámenes de situación, evaluación de sus sistemas de operación o condición de funcionamiento 0 a prevención o investigación de la legitimación de activos provenientes de ilícitos; h) información preparada por asesores jurídicos o abogados de la Administración Pública cuya publicidad pudiera revelar la estrategia a adoptarse en la defensa o tramitación de una causa judicial o divulgare las técnicas o procedimientos de investigación o cuando la información privare a una persona el pleno ejercicio de la garantía del debido proceso; i) cualquier tipo de información protegida por el secreto profesional; j) información que pueda ocasionar un
} 
Los sujetos pasivos están obligados a permitir el acceso a documentos administrativos en el momento en que les sea solicitado o proveerla en un plazo no mayor a ocho días en el estado en que se encontraren sin estar obligado a procesar o clasificar la información. Si transcurren treinta días hábiles sin que la autoridad competente brinde una respuesta al pedido de acceso a documentos administrativos o la misma fuese parcial, ambigua o inexacta, la solicitud se considera rechazada y se reconoce la posibilidad de interponer los recursos administrativos y/o acciones que el ordenamiento jurídico permita.

No entendemos que el pedido de vista amplio, introducido por la Ley $\mathrm{N}^{\mathrm{o}} 14.229$ de 2011 a la Ley de procedimiento administrativo, sea un caso particular del Acceso a la Información Pública sino que son institutos jurídicos distintos aún cuando en sus efectos puedan tener similitudes ${ }^{44}$. En efecto, el pedido de vista sólo se reconoce a la parte interesada y tiene efecto suspensivo de los plazos impugnatorios ${ }^{45}$, mientras que la solicitud de acceso a documentos administrativos requiere la acreditación de interés legítimo y no suspende plazo alguno. El concepto de interés legítimo de la Ley $\mathrm{N}^{\mathrm{o}} 12.475$, a pesar de lo limitado, es mucho más amplio que el de parte interesada contenido en la Ley de procedimiento administrativo, pues supone

peligro a la vida o seguridad de una persona; k) se trate de información protegida por leyes especiales (conf. arts. 16 y 18 del Anexo).

44 Art. 11 de la Ley Nº 7.647 según Ley N 14.229: "La parte interesada, su apoderado 0 letrado patrocinante, tendrán acceso al expediente durante todo su trámite, pudiendo, a su cargo, copiar o fotocopiar todas sus partes. El pedido de vista podrá hacerse verbalmente y se concederá sin necesidad de resolución expresa al efecto, en la oficina en que se encuentre el expediente, aunque no sea la mesa de entradas o receptoría. El párrafo anterior del presente artículo será exhibido en todas las reparticiones de la Administración centralizada, descentralizada y entes autárquicos al público".

45 Sobre este último efecto, en 2014, la Suprema Corte de Buenos Aires en "Müller, Gustavo Gastón c. Provincia de Buenos Aires y otro s/Pretensión anulatoria. Recurso extraordinario de inaplicabilidad de ley" reconoció que si bien el régimen de procedimientos administrativos no contiene una previsión expresa que confiera al pedido de vista el efecto automático o ex lege de suspender plazos impugnativos, los órganos de la Administración deben asignarle esa eficacia en virtud de la amplitud del derecho de libre acceso al expediente de la parte interesada, su apoderado o letrado patrocinante. 
derecho o interés legítimo más inicio de actuaciones ante la administración y que el carácter de parte sea reconocido por ésta como tal (art.10 Ley $\mathrm{N}^{\circ}$ 7.647). Más aún, dado que la Ley $\mathrm{N}^{\circ} 7.647$ señala que quien peticione con el objeto de lograr una decisión de la Administración comprendida en las facultades potestativas no será tenido por parte en el procedimiento ${ }^{46}$, a éste le puede ser negado el pedido de vista mientras que puede haber interés legítimo para acceder a información sobre qué hace la Administración con sus facultades potestativas pudiendo utilizar los recursos procedimentales de la Ley $\mathrm{N}^{\circ} 12.475$.

Finalmente, podemos destacar la Ley $\mathrm{N}^{\circ} 14.828$ sancionada en 2016 que aprobó el Plan Estratégico para la Modernización de la Administración Pública de la Provincia de Buenos Aires. Uno de los ejes de la reingeniería del Estado Provincial es el de mejorar la gestión pública a través de, entre otros, la reingeniería de procesos y sistemas de información de cada organismo y la promoción de la articulación entre éstos, lo que no sólo implica la interoperabilidad, esto es, que las áreas estatales puedan leer e intercambiar información, sino poder plasmar el derecho del ciudadano al único canal de entrada o "ventanilla única" para acceder a la información en poder del Ejecutivo sin necesidad de ir organismo por organismo ${ }^{47}$.

En esta línea se inscribe el Decreto $N^{\circ} 805 / 16$ que crea el portal de datos abiertos de la Provincia entre cuyos antecedentes que menciona se encuentra la Ley $\mathrm{N}^{\circ} \mathbf{1 2 . 4 7 5}$ y su Decreto Reglamentario, aunque sin pronunciarse explícitamente en qué medida la apertura modifica el estado normativo de la cuestión ${ }^{48}$.

46 Conf. art. $10^{\circ}$ Ley $N^{0} 7.647$.

47 Su Decreto reglamentario, № 1.018/16, prevé que el Sistema de Gestión Documental Electrónica Buenos Aires (GDEBA) operará como plataforma horizontal informática de generación de documentos y expedientes digitales creados por medios electrónicos, registros y otros contenedores a los fines de facilitar la gestión documental, el acceso y la perdurabilidad de la información, la reducción de los plazos en las tramitaciones y el seguimiento de cada expediente.

48 Entre sus considerandos hace una expresa mención al Acceso a la Información Pública al señalar " Que resulta ser una política pública del actual gobierno promover el derecho de acceso 


\section{Jurisprudencia sobre Acceso a la Información Pública en la Provincia de Buenos Aires}

En este acápite analizaremos el estado de la cuestión jurisprudencial de los últimos diez años. Para ello estudiaremos un fallo de la Cámara de Apelaciones en lo Contencioso Administrativo y tres fallos de la Suprema Corte de Justicia bonaerense sobre la temática donde podremos vislumbrar los alcances de la normativa bonaerense y las prácticas administrativas respecto al ejercicio de este derecho.

El primer caso que reseñamos es "Di Pietro, Marcelo Leonidas y otro c/Municipalidad de Babía Blanca s/amparo", del 20 de abril de 2006 y resuelto por la Cámara de Apelaciones en lo Contencioso Administrativo de La Plata. Marcelo Leonidas Di Pietro y Hernán Rodolfo Peter promovieron acción de amparo contra la Municipalidad de Bahía Blanca al no obtener por parte de dicho municipio el listado de beneficiarios de los planes de Jefas y Jefes de Hogar y demás planes de empleo y/o subsidios que administra la comuna. Incluyeron en la solicitud que se consignara en dicho listado los nombres, apellidos, números de documento y domicilio de los beneficiarios ${ }^{49}$. La solicitud, en

a la información pública, cuyo contenido evoluciona progresivamente desde su formulación clásica, promoviendo una adecuada publicidad de los actos que importa una práctica que atañe a la "buena administración". La mencionada publicidad coadyuva a la transparencia de la gestión pública, fortalece la relación de confianza entre los ciudadanos y el Estado, facilita los controles del obrar público y estimula la eficiencia y la efectividad de las administraciones" así como reconoce el valor instrumental del acceso a la información en orden a la libertad de expresión y al conocimiento de la cosa pública. Actualmente, el "Portal de Datos Abiertos de la Provincia de Buenos Aires" se encuentra en el sitio http://datos.gba.gob.ar/. Por formatos digitales abiertos, el Decreto $N^{0}$ 206/17 establece que son aquellos formatos que mejor faciliten su utilización, procesamiento, y redistribución por parte del solicitante. En cuanto a la utilidad de esta información a través del formato propuesto podemos señalar que permite en principio reutilizarla o interoperarla con sistemas que permitan una sistematización que genere aplicaciones o desarrollos tanto en beneficio del Estado como del Ciudadano, de allí su carácter reutilizable y el valor distinto a información estática o en formatos que no permitan ese tipo de uso y circulación.

49 Cabe señalar que el pedido que efectuaron lo hicieron como ciudadanos y también en carácter de candidatos a concejales por dicha comuna y como contribuyentes de dicho municipio. 
primer término, no obtuvo resultado y luego de un reclamo la respuesta fue negativa.

En el caso, la Cámara de Apelaciones en lo Contencioso Administrativo de La Plata, en el voto de la mayoría, señaló que la Ley $\mathrm{N}^{\mathrm{o}} 12.475 \ldots$

... viene a consagrar el acceso a la información como derecho individual, en tanto se configura como uno de los ejes de definición del acceso a la información exhibido como correlato de la libertad de expresión. Bajo este punto de vista, el acceso a la información se sitúa en el plano de justificación de los derechos individuales, y más específicamente, en el marco de los llamados derechos de libertad o derechos-autonomía, dirigidos a sustentar el espacio de autonomía personal de los individuos y a permitirles la realización de un plan de vida que se ajuste a su libre decisión.

Respecto a los actores entendió que no presentaban un interés especial, actual y directo que los habilitara para acceder a dicha información y señaló que la hipótesis de terceros en procura de información relativa a condiciones y datos de otras personas, con apoyo en el derecho a la información del artículo 12 inciso 4 de la Constitución local, amerita la armonía necesaria con el resguardo de la intimidad y privacidad, que es deber del Estado proteger. Expresamente señaló que "No es la cercanía o proximidad en la relación de vecindad del actor lo que determina el grado de legitimación, sin por el contrario el interés concurrente en relación a la pretensión esgrimida, es decir el modo en que amplía o se limita el círculo vital de derechos de la persona en relación a la información requerida".

Por ello, al no especificar en la solicitud cuál es el interés diferenciado que los ampara y en qué medida la indisponibilidad de la información se presenta como un agravio de no susceptible reparación para optar por la vía del amparo, no se dio lugar a dicha acción ${ }^{50}$.

50 Otra fue la mirada vertida en torno a la capacidad de legitimación que presentan los amparistas para el voto de la minoría. Según la Dra. Milanta, el hecho de que los actores 
Un cambio de orientación se advierte cuando la Suprema Corte de Justicia de la Provincia de Buenos Aires falla en los autos "Asociación por los Derechos Civiles contra Dirección General de Cultura y Educación. Amparo. Recursos extraordinarios de nulidad e inaplicabilidad de ley" de 2014. La Asociación por los Derechos Civiles dedujo acción de amparo a fin de que la Dirección General de Cultura y Educación de la Provincia de Buenos Aires brinde la información oportunamente requerida, relacionada con la cantidad de días de clases no dictadas en determinadas escuelas por ausencia de los docentes. Siguiendo y ampliando los fundamentos del juez de primera instancia, la Cámara de Apelación en lo Contencioso Administrativo de La Plata rechazó la acción de amparo por no reunir los recaudos exigidos por los arts. 1 y 2 de la entonces ley de amparo vigente, Ley $\mathrm{N}^{\mathrm{o}} 7.166$.

sean ciudadanos de Bahía Blanca denota una intensidad en el interés que esgrimen que se diferencia del común de cualquier ciudadano. A dicha circunstancia, se sumaba que la información la solicitaron en su carácter de candidatos a concejales lo cual adicionaba a su condición de vecinos una justificación diferencial en relación a cualquier ciudadano común. La Dra. Milanta planteó una solución intermedia para poder satisfacer los derechos de los amparistas por un lado y de los beneficiarios de los planes por el otro. Así planteó en su voto que la Administración puede proporcionar la información relativa a la selección y adjudicación de los planes sociales a través de datos objetivos y de las constancias obrantes en los registros públicos. Es decir, debió informar aspectos relativos a la distribución y actualización de las subvenciones de los aludidos programas.

Con argumentos similares en 2008, en "Suárez, Alejandro César c/Municipalidad de Florencio Varela s/amparo", la misma Cámara por mayoría negó el interés legítimo para acceder a información al titular del medio "Mi ciudad", quien promovió acción de amparo contra la Municipalidad de Florencio Varela para que dicha comuna le proporcione la nómina completa de empleados permanentes y contratados que allí prestan funciones, con el detalle de nombre y apellido, DNI, antigüedad, actividad desarrollada, área en la que se desempeña y sueldo; en 2013 en los autos "Asociación por los Derechos Civiles c/Jefatura de Gabinete de Ministros - Gobierno de la Provincia de Buenos Aires s/Amparo" también se rechazó un amparo por información referente a los gastos presupuestados y ejecutados en publicidad oficial para el periodo 2010 y 2011. Como veremos en los fallos de la Corte, interviene la misma Cámara con similares argumentos sin desconocer el antecedente de la Corte nacional, pero añadiendo ahora, como fundamento, que la limitación normativa local respecto al interés legítimo hace inaplicable el criterio amplio de acceso a la información pública. 
El voto de mayoría ${ }^{51}$ funda la condena a la Dirección General de Cultura y Educación para que en el perentorio plazo de 15 días ponga a disposición de la Asociación por los Derechos Civiles la información solicitada, en el amplio espectro normativo que avala el derecho al Acceso a la Información Pública más allá de las limitaciones de la ley local ${ }^{52}$.

Indicando que es un derecho que evoluciona progresivamente, la Corte entiende que el acceso a la información y documentación públicas recibe un amplio reconocimiento en el ordenamiento jurídico. En efecto, el voto se funda en el principio republicano de la Constitución y la Constitución provincial...

una de cuyas manifestaciones primordiales reside en la exigencia de publicidad de los actos de las autoridades del Estado. Con ello se procura que los ciudadanos puedan conocer los actos de gobierno, como modo de controlar a sus representantes, condición inherente a la democratización del poder.

Además de citar el Preámbulo y los arts.1, 14, 33 y 38, 41 y 42 de la Constitución Nacional, donde -señalan- la información es peculiarmente necesaria, remiten a los tratados con jerarquía internacional ${ }^{53}$ y las Convenciones Interamericana y de las Naciones Unidas contra la Corrupción además del art. 12 inc. $4^{\circ}$ de la Constitución provincial y reconocen que por regla general toda persona ha de tener acceso a la información pública.

Justamente por el carácter progresivo del derecho, más allá del interés legítimo requerido por la Ley provincial $\mathrm{N}^{\mathrm{o}} \mathbf{1 2 . 4 7 5}$, entiende que la misma estableció un piso mínimo y que por ello,

\footnotetext{
51 El voto de mayoría es de los jueces Soria, de Lázzari e Hitters y parcialmente Kogan.

52 El voto de la minoría señaló, además de replicar algunos argumentos de la Cámara, que dado que la información peticionada suponía un proceso de relevamiento de datos y no era un documento administrativo existente sino un documento a crearse, no debían computarse los plazos del decreto.

53 Destacan sólo la Convención Americana sobre Derechos Humanos, art. 13; la Declaración Universal de Derechos Humanos, art. 19.1; el Pacto Internacional de los Derechos Civiles y Políticos, art. 19.2.
} 
su Decreto reglamentario $\mathrm{N}^{\circ} 2.549 / 04$ al no requerir como la ley, interés legítimo, fue más amplio que aquella por lo que desde entonces en el ámbito del Ejecutivo toda persona puede solicitar el acceso a documentos administrativos de naturaleza pública “... sin necesidad de alegar fundamento o causa ni acreditar derecho o interés alguno". Y la doctrina del fallo agrega que...

el criterio rector, que mejor armoniza con el máximo rendimiento posible de los derechos y principios constitucionales implicados, es aquél conforme al cual la información generada o controlada por las autoridades estatales se presume pública y la carga de fundar una excepción a esta presunción recae sobre el ente gubernamental.

Un nuevo caso llega a la Corte provincial en 2016, "Albaytero, Juan Aníbal contra Municipalidad de Quilmes. Amparo. Recurso extraordinario de inaplicabilidad de ley" que se resuelve a favor del amparista que había solicitado información pública al municipio de referencia respecto del "Fondo de Inversión para Infraestructura e Intervenciones Urbanas" creado ${ }^{54}$. Si bien los cinco jueces consideraron fundado el recurso extraordinario de inaplicabilidad de $l e y^{55}$, el voto al que adhirió la mayoría fue

54 Específicamente solicitó información sobre 1) monto total de los ingresos percibidos por el municipio en concepto de la contribución especial antes mencionada, discriminado por período; 2) fecha de creación y puesta en funcionamiento del "Fondo de Inversión para Infraestructura e Intervenciones Urbanas"; 3) la incidencia que la Contribución Especial para el Fondo de Inversión para Infraestructura e Intervenciones Urbanas tiene en los ingresos totales del mismo (discriminada por períodos); 4) identificación de la totalidad de los proyectos, obras, contratos (locaciones, leasing, adquisiciones de bienes, insumos, contratación de personal, gastos fijos y variables, etc.) financiados por dicho fondo y; por último, 5) la individualización de la cuenta bancaria en la que se centraliza la operatoria del Fondo de Inversión para Infraestructura e Intervenciones Urbanas y un resumen completo de los movimientos de la misma.

55 En el caso, el Tribunal Oral Criminal $n^{0} 4$ del Departamento Judicial Quilmes había declarado abstracta la cuestión sometida a juzgamiento dado que el municipio cumplió con posterioridad a iniciado el amparo cuando brindó información relativa a los montos recaudados correspondiente a los períodos de enero a octubre del año 2011, e indicó que el referido Fondo fue creado por la Ordenanza municipal 11.603/10. A su vez la Cámara de Apelación en 
el del juez Daniel Fernando Soria que fue quien fijo las bases del fallo anterior, por lo que sólo destacaremos ahora elementos nuevos respecto del fallo anterior ${ }^{56}$.

El voto de mayoría, siguiendo el criterio expresado por la Corte Suprema de Justicia de la Nación en el caso "CIPPEC c/Min. de Desarrollo Social- dto. 1172/03, Amparo ley 16.986", señala que las respuestas vagas o genéricas brindadas por el Municipio no son una contestación adecuada con lo relacionado a la puesta en funcionamiento del fondo, punto neurálgico del requerimiento informativo planteado. También rechaza la afirmación del Municipio respecto a lo imposible o injustificadamente costoso de los trabajos adicionales para poder brindar datos por hacerlo sin mayor fundamento ni explicitar los motivos.

Por último, negó que las cuentas bancarias utilizadas para realizar operaciones con fondos públicos constituyan "información sensible", o que en principio, contengan datos que deban mantenerse en reserva o en secreto.

El tercer caso de la Corte provincial es de marzo de 2017. En los autos "Longarini, Cristian Ezequiel y otros contra Ministerio de la Producción y otros. Amparo. Recurso extraordinario de inaplicabilidad de ley", los actores, por derecho propio como vecinos afectados en su salud, en su propio interés y en el de la colectividad, dedujeron acción de amparo ambiental contra el Ministerio de Asuntos Agrarios y Producción y la Secretaría de Política Ambiental de la Provincia de Buenos Aires, luego OPDS, aduciendo como fundamento de su demanda, omisiones en el control por parte de la autoridad pública respecto del establecimiento industrial propiedad de la empresa Atanor S.A., solicitando, entre otras peticiones, que la Provincia brinde

\footnotetext{
lo Contencioso Administrativo de La Plata rechazó el recurso de apelación al señalar que en el caso no se configura una conducta omisiva arbitraria o ilegítima y que el amparista no exhibe un interés actual y directo que justifique la condena judicial que persigue, además de considerar, respecto del amparo, que el perjuicio alegado no es actual o inminente.

56 Genoud, Kogan y de Lázzari adhirieron al voto de Soria mientras que Pettigiani lo hizo según su voto.
} 
información ambiental veraz, completa e irrestricta referida a la planta y de toda otra radicada en la zona del conflicto ambiental, exigiéndose la remisión al juzgado de las constancias y antecedentes existentes en los organismos o entidades públicas provinciales, incluida la Autoridad del Agua, referidos a mediciones, análisis y resultados de estudios del aire, suelo, subsuelo y napas freáticas, realizados dentro de la citada planta y en su zona de influencia ${ }^{57}$.

En el caso, los jueces de instancias inferiores respecto a la temática de acceso a la información pública, rechazaron la demanda porque los accionantes no acreditaron haber solicitado oportunamente información ambiental a la entonces Secretaría de Política Ambiental.

En un complejo caso, que demandó que la Corte requiriera varias medidas para mejor proveer y basándose en normativa ambiental (art. 41 de la Constitución nacional; 28 de la Constitución provincial, arts. 2, inc. i) y 16 a 18 de la Ley $\mathrm{N}^{\circ} 25.675$; art. $3^{\circ}$ Ley $\mathrm{N}^{\circ} 25.831$ ), si bien reconoció que hay constancias en la causa que evidencian que la autoridad pública demandada brindó en autos información existente en diversas tramitaciones administrativas, también entendió que el mismo es un derecho que no se agota por lo que subsiste el interés de los reclamantes en recibir información actualizada de modo permanente y eficaz.

Así condenó al O.P.D.S. a que cada seis meses efectúe los correspondientes estudios de monitoreo del suelo, subsuelo y napas freáticas y emisiones a la atmósfera, permitiendo el libre acceso a la información a los accionantes y a los habitantes de la zona de influencia, habilitándose su participación durante la ejecución de las acciones llevadas a cabo para cumplir con los parámetros impuestos por la normativa ambiental (arts. 41, C.N.; 28, Const. prov.; 19, 20 y 21, Ley No 25.675).

57 Requirieron también la remisión de las actuaciones relativas a la aplicación de sanciones a la aludida planta industrial, tanto por autoridades provinciales como municipales, y si existiere en trámite un procedimiento de evaluación de impacto ambiental, copia del expediente respectivo y un informe acerca de su estado. 


\section{Conclusiones}

Estamos en un período paradigmático del derecho que deja en evidencia la falta de cohesión e integralidad normativa: se advierte una autentica pluralidad de fuentes vinculantes que conforman distintos estratos de juridificación que no son uniformes ni idénticos (Conf. Corvalán, 2016) ${ }^{58}$. El caso del derecho de acceso a la información pública en la provincia de Buenos Aires es un claro ejemplo de ello, un instituto jurídico donde conviven tratados internacionales, normas constitucionales nacionales y locales, leyes restrictivas, reglamentaciones amplias para uno de los poderes del Estado y silencio en los otros, todo ello en un campo de acción administrativo e interpretativo jurisdiccional no ajeno a conflictos.

Este "derecho sobre el derecho" en la terminología de Ferrajoli (2011) es, en nuestro caso, un derecho no sólo de reciente cristalización sino que se encuentra todavía hoy en progresiva evolución. La clave de bóveda de todo este instituto es y debe ser el más amplio derecho posible para el acceso ciudadano a la información pública pues es el único compatible con el sistema democrático y de los derechos humanos.

En efecto, desde el punto de vista jurídico-constitucional y dado que la corrupción fue definida por nuestro constituyente como un atentado contra el sistema democrático, el acceso a la información pública es necesario para el ejercicio de un control real y racional de la cosa pública ${ }^{59}$ y para un ejercicio legítimo del gobierno. El titular del bien jurídico vinculado al desempeño ético de la función pública es la ciudadanía toda pues es

\footnotetext{
58 Siguiendo al autor, la estratificación de la juridicidad presenta múltiples y diversas capas de procedencia, jerarquía e intensidad y se integran por componentes "infra" y "supra" estatales. La "estratificación de la juridicidad se perfecciona por la presencia de normas jurídicas condicionantes y a su vez condicionadas, en casi todas las capas y a partir de una multiplicidad y diversidad de fuentes. Entonces ya no se resuelve el tema en la ecuación "Constitución- leyreglamento" (Corvalán, 2015:62).

59 La transparencia previene las opiniones públicas irreflexivas, la opacidad las promueve.
} 
un derecho que afecta al sistema democrático ${ }^{60}$. Y si bien es cierto que la opacidad no supone per se la corrupción, aquélla es su precondición.

Por otro lado, el acceso a la información pública es claramente uno de los ejes del ejercicio de la libertad y en ese marco se ha consolidando como derecho humano a partir de la interpretación dada por la Corte Interamericana de Derechos Humanos sobre la base del clásico derecho de Libertad de Pensamiento y de Expresión reconocido como artículo 13 de la Convención Americana de Derechos Humanos.

Hemos señalado que el derecho de acceso a la información pública en la provincia de Buenos Aires es un ejemplo de estratificación de la juridicidad y podemos dar cuenta de ello: por un lado, reconocido genéricamente el derecho constitucional de acceso a la información, a nivel legislativo se cuenta con una norma, la Ley $\mathrm{N}^{\mathrm{0}} \mathbf{1 2 . 4 7 5}$, que permite el acceso sólo a los documentos administrativos y a quien acredite un interés legítimo; sin embargo, la norma que la reglamenta cuatro años más tarde, Decreto $N^{\circ} 2549 / 04$, omite la acreditación del interés legítimo ${ }^{61}$, requisito que tanto la Administración Pública como diversos tribunales han seguido exigiendo hasta que la Suprema Corte de Justicia en 2014, recurriendo a principios, normas y fallos internacionales y nacionales reconoce un derecho amplio de acceso a la información pública. De todas formas, esta limitación aún sigue estando vigente no sólo en las normas sino también en las prácticas administrativas por lo que se requiere una urgente modificación.

\footnotetext{
60 Sin dudas estamos frente a un nuevo derecho de incidencia colectiva que se halla en cabeza de los ciudadanos y en tal sentido les cabe la legitimación prevista en el artículo 43 de la Constitución Nacional. En igual sentido Gelli (2016) señala que dada la amplia legitimación que la Corte de la Nación le da a este derecho, estamos frente a una acción popular.

61 Otro claro ejemplo de los conceptos "fragmentación de la legalidad", "extensión del principio de legalidad", o "inflación de las leyes", conceptos que reseñan este nuevo esquema normativo no-piramidal donde las normas legislativas, por ambigüedad, insuficiencia o delegación son a su vez reguladas, limitadas, aclaradas o completadas por otras normas aún de menor jerarquía.
} 
No obstante la relación de subordinación jurídica típica de nuestro régimen constitucional al bloque federal y la crítica a las diferencias normativas habidas, creemos que debe optarse por una política legislativa provinciana genuina como expresión de la autonomía política y administrativa, con las implicancias orgánicas y estructurales que requiere un régimen que responda a la estratificación organizacional provincial ${ }^{62}$.

Ya han pasado más de 17 años desde la sanción de la Ley $\mathrm{N}^{\mathrm{o}} 12.475$ y han habido varios proyectos de ley sobre el derecho de acceso a la información pública, lo que da cuenta de la necesidad de la modificación del actual marco normativo ${ }^{63}$. En esa necesaria actualización, las referencias a los derechos humanos y al sistema democrático no pueden faltar, tal como ya fuera recocido por la jurisprudencia internacional, la Corte Suprema de Justicia y la ley nacional.

Además de los principios de publicidad, celeridad, informalidad, accesibilidad, igualdad y gratuidad ya vigentes en el decreto local, y los de legitimidad activa amplia, transparencia activa, presunción de publicidad de toda la información en poder del Estado, máximo acceso, accesibilidad en formatos electrónicos abiertos, no discriminación, responsabilidad, facilitación, buena fe, in dubio pro petitor, disociación, control y alcance limitado de las excepciones, principios presentes en el ámbito nacional que debería replicar la futura legislación provincial, pueden proyectarse algunas otras, habida cuenta de la experiencia tales como la prohibición expresa de delegación o reglamentación del derecho por los órganos estatales ${ }^{64}$,

\footnotetext{
62 El art. 36 de la Ley № 27.275 invita a la adhesión de las provincias, producto de una técnica legislativa que se ha vuelto habitual en los últimos años. Sin embargo, el mimetismo normativo no asegura la necesaria coherencia cuando las estructuras institucionales son distintas.

63 En Diputados, los proyectos D- 1949/10-11- 0, D- 964/11-12- 0 y D- 1992/11-12- 0. En el Senado, E 5092016 - 2017, E 4462016 - 2017, E 612016 - 2017, E 232016 - 2017, E 1652014 - 2015, E 962013 - 2014, E 2742012 - 2013, E 1032012 - 2013, E 72012 - 2013, E 4442010 - 2011, E 82009 - 2010, E 2212008 - 2009, E 402005 - 2006, E 352004 - 2005, E 542003 - 2004, E 162001 - 2002.

64 En este sentido, la ley debe ser completa, amplia y autosustentable. El principio de base mínima de la ley no es suficiente pues generalmente las reglamentaciones suelen ser más restrictivas que la norma general.
} 
el profesionalismo en las respuestas para garantizar su eficiencia y eficacia; la verificabilidad, para permitir el acceso a las fuentes de la información y controlar su completitud y/o inexistencia alegada, la sencillez del lenguaje o procesamiento de los datos, para que no se requieran ulteriores procesamientos o "traducciones".

El acceso, dado el creciente uso de las plataformas electrónicas para los diversos trámites administrativos, también requerirá la generación de usuarios y claves a los ciudadanos para poder no sólo "seguir" sus propios trámites sino cualquier otro.

Por último, antes que la creación de nuevos órganos especializados o Consejos pluripartitos, que terminan bajo la dependencia del Poder Ejecutivo, proponemos reforzar las competencias del defensor del pueblo, dado el carácter de derecho colectivo del que estamos tratando, sus competencias constitucionales asignadas y la plena autonomía funcional y política que debe tener (conf. art. 55 de la Constitución de la Provincia).

Ante este panorama, el normativo no es el único aspecto sobre la cual resulta necesario innovar: de nada sirve crear un régimen o adherir a otro sin una visión garantista que en la práctica se plasme en la necesaria colaboración orgánica inter-poderes e inter-administrativa para acceder a la información pública. Sin la promoción de una cultura de apertura y transparencia, y habida cuenta de la atomización organizacional del Estado, estaremos sólo promoviendo un acceso condicionado a la judicialización del derecho o a un triste peregrinar del ciudadano entre distintos organismos.

\section{Bibliografía}

Basterra M. (2017). Acceso a la Información Pública y transparencia. Ley 27.275 y decreto reglamentario 206/17. Comentados, anotados y concordados. Edición Astrea. Buenos Aires.

Berardi, C. J. (2018). "El acceso a la información pública. Alcances limitados de un derecho fundamental" en Revista Argentina 
del Régimen de la Administración Pública $\mathrm{N}^{\circ}$ 470. Buenos Aires, Argentina.

Buteler, A. (2012). "Corrupción y derecho administrativo" en Revista de Direito Administrativo \& Constitucional, ano 12 - n. 48, abril/junho - 2012 Belo Horizonte. En línea en www.revistaaec. com/index.php/revistaaec/article/download/181/231

Carello, L., (1998). "La Convención Interamericana contra la Corrupción y el 'derecho a la no corrupción'”, en $A A V V$ Defensoría del Pueblo. 50 años de Derechos Humanos. Santa Fe, Argentina. cit. por Gordillo, A., (2009) "Hacia la unidad del orden jurídico mundial", en $A A V V$ El Nuevo derecho administrativo global en América Latina. Edición RAP. Buenos Aires. Argentina.

Corvalán, J. G. (2015). Discrecionalidad administrativa y tributaria. Tesis doctoral, USAL. Disponible en http://www.ninc.com. br/img/pesquisa/arquivo_20150819190539_49.pdf

Corvalán, J. G. (2016). Derecho Administrativo en transición. Reconfiguración de la relación entre la administración, las normas y el Poder Judicial. Reglas y principios. Discrecionalidad débil y fuerte. Valoración, interpretación y ponderación. Control judicial y políticas públicas. Edición Astrea. Buenos Aires, Argentina.

Díaz Cafferata, S. (2009). "El derecho de acceso a la información pública” en Lecciones y Ensayos. Nro. 86. Buenos Aires, Argentina. Ekmekdjian, M. A., (1994). Tratado de Derecho Constitucional. Tomo I, Ediciones Depalma. Buenos Aires, Argentina.

Ferrajoli L. (2011). Principia iuris. Teoría del derecho y de la democracia. Edición Trotta. Madrid.

Funes, F. J. y Rivas, F. (2016) "Ley de Acceso a la Información Pública: un avance en pos de la democracia republicana y un afianzamiento del Estado constitucional de derecho" en La Ley. Buenos Aires, Argentina.

Gelli, M. A. (2016). "Ley de acceso a la información pública, los principios, los sujetos obligados y las excepciones", en La Ley. Número 1040. Buenos Aires, Argentina.

Gordillo, A. (2017). "La corrupción como delito de lesa humanidad" en Revista Jurídica de San Luis. Número 1 - Mayo. San Luis, Argentina. 
Ivanega, M. M. (2016). Control Público. Edición Astrea. Buenos Aires, Argentina.

Oszlak, O. y Kaufman, E. (2014). Teoría y práctica del gobierno abierto: Lecciones de la experiencia internacional. IDRC; RedGealc; OEA. Organización de los Estados Americanos.

Vallefín, C. A. (2009) El acceso a la información pública. Una introducción. Edición Hoc. Buenos Aires, Argentina.

Vallefín, C. A. y López, J. I., (2017). “Anotaciones a la ley 27.275 de Acceso a la Información Pública: sinopsis y comparación con el régimen anterior" en Suplemento Jurisprudencia Argentina. Tomo I. Buenos Aires, Argentina. 